\title{
FORMAÇ̃̃O CONTINUADA DE PROFESSORES: A EXPERIÊNCIA DO PROGRAMA DE RESIDÊNCIA DOCENTE NO COLÉGIO PEDRO I*
}

\author{
Neide da Fonseca P. Sant'Anna** \\ Colégio Pedro II (CPII) \\ Francisco Roberto P. Mattos*** \\ Universidade do Estado do Rio de Janeiro (UERJ) \\ Christine Sertã Costa ${ }^{\cdots \cdot *}$ \\ Pontifícia Universidade Católica do Rio de Janeiro (PUC-Rio)
}

RESUMO: Este artigo discorre sobre o Programa de Residência Docente do Colégio Pedro II, que se caracteriza como uma realização de Terceiro Espaço na formação de professores. Elaborado para oferecer a professores das redes públicas do Rio de Janeiro uma experiência de formação continuada, o Programa constitui uma realidade de interação entre pesquisa acadêmica e prática docente. Emprega a vivência em uma escola pública de qualidade para potencializar as ações docentes nas realidades escolares de origem dos participantes. Contribui tanto para elevar a qualidade da formação profissional quanto para propiciar a discussão da realidade educacional. Levado à prática em 2012, oferece a professores recém-formados uma inserção em um projeto que contempla pesquisa, teoria e prática para o aprimoramento do exercício da docência e culmina na concessão do título de especialista. São aqui examinadas a concepção e a estrutura do Programa em sua primeira aplicação bem como o desenvolvimento e a avaliação de sua implementação. Além disso, são identificadas quatro categorias fundamentais de conflitos vivenciados pelos professores recém-formados por meio de relatos extraídos dos produtos do Programa, que são analisados com o respaldo do conceito de Terceiro Espaço.

Palavras-chave: Formação continuada. Residência docente. Aprimoramento docente.

http://dx.doi.org/10.1590/0102-4698139566

" 0 Programa de Residência Docente do Colégio Pedro Il conta com o financiamento e 0 apoio acadêmico. institucional da CAPES.

"* Doutora em Educação pela Pontifícia Universidade Católica do Rio de Janeiro (PUC-Rio). Professora Aposentada do Colégio Pedro ll e Docente do Programa de Mestrado Profissional em Práticas de Educação Básica (MPPEB-CPII). Integrante do Núcleo de Estudos de Residência Docente e Práticas de Educação Básica. E-mail: neidefps@gmail.com

“* Doutor em Engenharia de Sistemas e Computação pela Universidade Federal do Rio de Janeiro COPPE/ UFRJ. Professor do Colégio Pedro II. Coordenador do Programa de Mestrado Profissional em Práticas de Educação Básica (MPPEB-CPII). Docente do Departamento de Matemática e Desenho do Instituto de Aplicação - UERJ. Integrante do Núcleo de Estudos de Residência Docente e Práticas de Educação Básica. E-mail: francisco.mattos@gmail.com

"*** Doutora em Engenharia de Produção pela Universidade Federal do Rio de Janeiro COPPE/UFRJ. Professora do Colégio Pedro II e Docente do Programa de Mestrado Profissional em Práticas de Educação Básica (MPPEB-CPII). Coordenadora da Especialização Programa de Residência Docente (PRD-CPII) Docente do Departamento de Matemática da PUC-Rio. Integrante do Núcleo de Estudos de Residência Docente e Práticas de Educação Básica. E-mail: cserta@globo.com 


\title{
CONTINUING EDUCATION FOR TEACHERS: COLÉGIO PEDRO II'S TEACHER RESIDENCY PROGRAM EXPERIENCE
}

\begin{abstract}
This article discusses the Colégio Pedro II's Teachers Residency Program, which features as a realization of Third Space in the qualification of teachers. The program is a reality in interaction between academic research and teaching practice. It employs experience in a good quality public school to enhance the quality of teaching actions in the participants' school realities. The program contributes both to improve resident's professional training quality and to provide a discussion about education's reality. It offers graduated teachers an insertion on a project that includes research, theory and practice and culminates in awarding the title of Specialist. Here are examined the design and structure of the program and the development of its implementation. In addition, four basic kinds of conflicts experienced by recently graduated teachers are identified in the students' reports on the program products. The analysis of such conflicts is supported by the concept of Third Space.
\end{abstract}

Keywords: Continuous training. Home teacher. Teacher improvement.

\section{INTRODUÇÃO}

Analisando estudos da última década (ROCHA et al., 2013; NEUBAUER; SILVEIRA, 2009), é possível perceber a insatisfação da sociedade diante das políticas educacionais voltadas para a Educação Básica - uma vez que a ineficiência da educação se reflete, claramente, nas desigualdades sociais tão acentuadas no Brasil. Recentemente, porém, é possível observar maiores esforços de setores públicos em trazer mudanças nesta área, especialmente a partir do Plano de Desenvolvimento da Educação, PDE (BRASIL, 2007), que tem como dois de principais pilares a formação de professores em suas variantes institucionais e a valorização dos profissionais da educação. O PDE estabelece metas e diretrizes que comprometem, em definitivo, a União com a formação (inicial) de professores para os sistemas públicos de educação básica por meio da Universidade Aberta do Brasil - UAB - e o Programa Institucional de Bolsas de Iniciação à Docência - PIBID. Assim, a Coordenação de Aperfeiçoamento de Pessoal de Nível Superior - CAPES passa a fomentar a formação de pessoal de nível superior para todos os níveis da educação e não apenas para atuação no nível superior.

A UAB e o PIBID, por seu turno, alteram o quadro atual da formação de professores, estabelecendo relação permanente entre educação superior e educação básica. É o embrião de um futuro sistema nacional público de formação de professores, 
no qual a União, por meio da Fundação Coordenação de Aperfeiçoamento de Pessoal de Nível Superior (CAPES), assume enfim uma responsabilidade que, a rigor, sempre foi sua. (BRASIL, 2007, p. 15)

Fruto dessa institucionalização, os programas propostos nas metas do PDE adquirem a dimensão de programas de Estado, sustentáveis em longo prazo, ao invés de ações historicamente baseadas em convênios unidimensionais e temporários. A variedade de estratégias para capacitar o profissional da sala de aula e dar-lhe ferramentas para atuação mais eficaz nas diferentes realidades em que se situa pode mitigar muitos dos problemas da Educação Básica Brasileira.

Dentro desse contexto, o Colégio Pedro II estrutura um projeto para contribuir com a melhoria do ensino por meio de uma formação continuada, visando partilhar a sua experiência bem sucedida na Educação Básica. Este artigo apresenta o projeto denominado "Programa de Residência Docente" no Colégio Pedro II, que, apoiado em uma estrutura de curso de especialização sui generis, com o fomento da CAPES, busca parear professores recém-formados e ingressantes nas redes públicas com a expertise pedagógica acumulada do Colégio Pedro II. Assim, o Programa de Residência Docente - PRD visa possibilitar a translação de conhecimentos pedagógicos empíricos, vivenciados em uma escola de bons resultados, a outras realidades diversas através de vivência, reflexão, experimentação e construção de conhecimentos entre pares. A formatação do projeto busca possibilitar a articulação entre a formação específica de cada professor residente e a experiência de uma supervisão acadêmica e aplicada sobre os diversos modos da prática de sala de aula. O Programa é executado por edital público e convênios com as Secretarias de Educação, estabelecendo uma logística para a atuação do professor residente e garantindo as condições necessárias para a realização das atividades que compõem os requisitos de um 'curso' de especialização que compreende, ainda, preparação de relatórios, elaboração de material didático, e participação em projeto de pesquisa da instituição.

A possibilidade de os professores iniciantes fazerem relação do que aprenderam em sua formação inicial com a vivência na prática profissional constitui-se em um dos pilares desse Programa. Desse modo, o Programa atua na difícil associação ou adequação das habilidades e conhecimentos adquiridos na formação inicial com a prática e a realidade vivenciadas em sala de aula, no tratamento das disciplinas específicas, bem como em relação às questões de integração social nas relações sociais entre alunos e entre alunos-professor.

[...] raramente acontece que essa formação teórica não tenha de ser completada com uma formação prática, isto é, com uma experiência direta do trabalho, 
experiência essa de duração variável e graças à qual o trabalhador se familiariza com seu ambiente e assimila progressivamente os saberes necessários à realização de suas tarefas. (TARDIF; RAYMOND, 2000, p. 211)

No caso das práticas escolares, inclui-se como importante fator de desenvolvimento docente o apoio advindo do convívio com outros profissionais da educação, mais experientes - o que pode contribuir para a construção do perfil do docente iniciante no trabalho escolar. $\mathrm{Na}$ maioria dos casos, na passagem de aluno a professor de fato, o profissional passa por um período de transição, que tem como referências básicas os modelos aprendidos na formação inicial, ou o que ele carrega desde o tempo de aluno naquela fase do ensino. Mas, para atuar em seu novo papel e enfrentar a realidade pragmática, muitas vezes tão diferente da sua própria vivência como estudante, há que se criarem novas posturas e atitudes, bem como se redirecionarem as habilidades profissionais de modo que atendam às demandas diferenciadas que se colocam ao jovem professor. Um grande alicerce desse reposicionamento do docente é o fomento de ações reflexivas, de atuação consciente, ponderada e analítica, deslocando o agir reprodutivo (seguindo orientações ou instruções recebidas na formação inicial) para um agir reflexivo e questionador. A prática reflexiva conduzida isoladamente pelo professor, porém, é limitada, como apontam Garrido e Carvalho (1999). As autoras nos alertam que:

Ao interpretar as situações de ensino e tomar decisões, o professor o faz de acordo com suas "representações alternativas" que se mostram resistentes à mudança. Sem um parceiro que exerça de forma sistemática e consciente a tarefa questionadora e provocadora que o professor realiza junto aos alunos instigandoas à mudança, a reflexão que empreende sobre sua prática teria dificuldade de avançar. A presença do professor, em cursos de formação inicial, ou do pesquisador, nos casos de formação em serviço, passa a exercer o importante papel de estimulador de mudanças didáticas, oferecendo suporte e contextos, e monitorando o processo de mudança antes que ela possa ser exercida pelo próprio licenciando. (GARRIDO; CARVALHO, 1999, p. 153)

Tendo presentes todos esses aspectos, o Programa de Residência Docente foi planejado como um Terceiro Espaço no sentido de Zeichner (2010). O espaço escolar oferecido pelo Programa de Residência Docente pretende ser um lócus de vivências, de experimentação, de observação-participativa e de construção de saberes docentes, através de exposição a novas teorias, novas práticas e novos olhares sobre as tarefas milenares de ensinar e aprender. As premissas, procedimentos e componentes da programação do Programa serão apresentados e discutidos no presente artigo. 


\section{O TERCEIRO ESPAC̣O NA FORMAC̣ÃO CONTINUADA DE PROFESSORES}

A criação do Programa de Residência Docente tem seu fundamento teórico no conceito de "Terceiro Espaço" (third space). A extensãodoconceitode Terceiro Espaçoàárea educacional(ZEICHNER, 2010) considera as interfaces entre meio acadêmico e realidade escolar, locais em que se desenvolvem sinergias entre a experiência concreta e a formulação teórica, entre a conceituação e a vivência prática.

Segundo Zeichner (2010) o Terceiro Espaço advém da teoria do hibridismo (BHABBA, 1990; 1994) que reconhece que

os indivíduos se apropriam de múltiplos discursos para dar sentido ao mundo e envolve uma rejeição de oposições entre os polos do conhecimento acadêmico e do saber prático. Neste, se exploram novas formas de integração do que é visto como discursos concorrentes, em uma perspectiva disjuntiva, do tipo "ou", se transforma em um ponto de vista "ambos/também”. (ZEICHNER, 2010, p. 92)

Essa teoria tem sido utilizada em geografia, artes, estudos pós-coloniais, estudos feministas e, mais recentemente, em educação (por exemplo, GUTIÉRREZ, 2008; MOJE et.al., 2004; SOJA, 1996), incluindo a formação de professores (COCHRAN-SMITH; LYTLE, 1999; WILLIAMS, 2014).

$\mathrm{Na}$ educação, atende a dois objetivos: melhorar a formação de professores e ampliar a sua capacidade de aprender a partir da prática; e desenvolver a pesquisa científica na área de educação pelo aumento da interação entre profissionais da educação, gestores e pesquisadores.

O modelo hoje em dia dominante na Formação de Professores se baseia em uma dicotomia entre aprender a teoria da educação na universidade e aplicá-la na prática de ensino nas escolas. Futuros professores vão às escolas "praticar" o que aprendem na universidade. Outro aspecto desse modelo é a marginalização do conhecimento de professores com prática na sala de aula, de tal modo que a pesquisa na universidade desconhece o conhecimento acadêmico que é gerado a partir da prática nas escolas. Mais ainda, mesmo no meio acadêmico, a pesquisa em ensino é vista como desenvolvimento profissional e não como criação de conhecimento.

Isso é explicado pela falta de incentivos para que professores do corpo docente permanente da universidade invistam tempo na coordenação entre as atividades no campus e as desenvolvidas na prática docente dos alunos e de autoridade para interferirem nas instituições externas (BULLOUGH et al, 1997; BULLOUGH et al, 2004; CORNBLETH; ELLSWORTH, 1994; ZEICHNER, 2002). 
Apesar de muitos programas incluirem experiências de campo no currículo, o tempo que os estudantes passam nas escolas muitas vezes não é cuidadosamente planejado. Zeichner (1996) registra que, muitas vezes, o processo de alocação dos alunos é "terceirizado" a um escritório de colocação administrativo central em vez de ser baseado em departamentos, e obedece a considerações administrativas e não ao que é melhor para a aprendizagem dos futuros professores. Os futuros professores são muitas vezes deixados para trabalhar por si mesmos, com pouca orientação, de modo que as boas práticas de ensino são capturadas em vez de ensinadas (DARLINGHAMMOND, 2009 ; VALENCIA et al., 2009).

Zeichner (2010) destaca exemplos na área educacional. O primeiro é desenvolvido na Universidade de Wisconsin-Madison, uma das instituições em que, embora sempre tenha havido a presença dos pesquisadores no ensino e no acompanhamento dos estágios docentes dos alunos da graduação, a distância entre teoria e prática (CLIFFORD; GUTHRIE, 1988; GOODLAD, 1990; LABAREE, 2004, VICK, 2006) vinha sendo amplamente discutida. No novo programa, para criar uma ligação mais forte entre a preparação acadêmica dos novos professores e a experiência dos professores com longa prática nas escolas, professores que demonstraram elevada competência na sala de aula são trazidos para passar dois anos participando de todas as etapas da formação dos alunos, incluindo seleção, ciclo básico, ciclo profissional, avaliação do curso e apoio aos alunos nos primeiros anos em atividade nas escolas. Ao mesmo tempo participam de seminários para ampliar a sua qualificação.

$\mathrm{Na}$ mesma direção vai o trabalho da Carnegie Foundation for Advancement of Teaching para criar representações na internet de práticas de ensino (POINTER-MACE, 2009). Com base nesses vídeos, os professores da Universidade criam seus próprios sites para uso dos seus alunos.

Outros exemplos, trazidos por Gallas e Look (2004), envolvem a inclusão no currículo dos cursos de formação de professores disciplinas em que o aluno estuda os trabalhos publicados por professores sobre a sua prática nos diversos níveis do ensino.

Há também exemplos de parte do curso universitário sendo oferecida em escolas. Um exemplo citado por Zechner (2010) é o da University of Washington - Seattle em que metade das aulas de Matemática de cada semana é dada em uma escola em que a metodologia ensinada no curso está sendo aplicada. Nessas aulas, as experiências dos professores na escola são apresentadas e discutidas. 
Assim, a nova visão das Práticas em Formação de Professores com o emprego da noção de Terceiro Espaço representa uma mudança de paradigma epistemológico. É nesse novo paradigma que se desenvolve o Programa de Residência Docente com as características que apresentamos no tópico seguinte.

\section{A CONCEPÇÃO DA RESIDÊNCIA DOCENTE}

Profissões que requerem experiência prática para consolidar a ponte entre o saber teórico e a aplicação às diferentes realidades têm como característica relevante na boa formação de seus profissionais a imersão na vida profissional durante a formação universitária. Talvez a mais consolidada experiência nesse sentido seja a da formação médica, em que os futuros profissionais se inserem na vida hospitalar ao longo de seu curso e ao concluí-lo, são estimulados a buscar uma especialização ou polimento de sua formação geral em um período de residência. É notável a concorrência para vagas de residência médica nos grandes centros de saúde e amplamente reconhecida a importância dessa fase de capacitação profissional. É característica dessa fase a

aquisição progressiva de responsabilidade pelos atos profissionais; desenvolvimento da capacidade de iniciativa, julgamento e avaliação; internalização de preceitos e normas éticas; e o desenvolvimento de espírito crítico. Todas essas funções fazem com que a residência médica represente um marco profundo no perfil profissional do futuro médico. (BOTTI; REGO, 2010, p. 133)

É uma etapa que permite integrar conhecimentos diversos aprendidos em várias disciplinas de sua formação universitária, muitas vezes, desvinculadas, com a experiência in loco e, dessa forma, aprender a avaliar situações, desvendar estratégias de enfrentamento dos problemas e definir soluções para os desafios, aplicar os conhecimentos mais adequados para realizar a missão profissional.

O Projeto da Residência Docente aqui apresentado inspirase nessa imersão em contexto profissional de categoria reconhecida daquele que é recém-graduado, para abrir-lhe novos horizontes, complementar sua formação e criar posturas éticas e proativas necessárias ao bom exercício profissional.

Poder-se-ia argumentar que, na Licenciatura, especialmente nos períodos das chamadas Práticas de Ensino, o licenciando está inserido em contexto escolar e, aparentemente, absorvendo as vivências que lhe complementariam a formação para ensinar. No entanto, embora tenha havido um aumento substancial da inserção 
escolar e/ou atividades didáticas e práticas com a Resolução CFE/ CP n. 2/2002 (BRASIL, 2002) que ampliou para 400 horas o estágio curricular, sabe-se que o licenciando ministra poucas aulas, não acompanha o processo educacional de forma ativa, limitando-se quase sempre à observação de aulas, frequentemente, em período pontual por não estar presente ao longo do ano letivo. Sua vivência escolar é, também, na maioria das vezes, restrita à sala de aula, sem que tenha oportunidade de ver como se integram as demais esferas escolares (como orientação pedagógica, coordenação e setores diversos, como a biblioteca, por exemplo). E, ainda, não observa os alunos em outras interações fora da sala de aula que assiste - como em outras aulas de disciplinas diferentes. A falta dessa abertura a outros espaços o isola e reforça a segregação entre disciplinas, dificultando a construção de uma visão inter/transdisciplinar.

Há ainda que se salientar que a pouca participação do licenciando em fases diferentes do processo pedagógico, como preparação de aulas, de materiais, de instrumentos de avaliação, de correção e de criação de estratégias de apoio a dificuldades específicas, o prepara somente parcialmente para a vida profissional que terá que exercer. Entendendo que estas outras ações são essenciais e integrantes do processo educativo, a não experimentação com tais atividades pode gerar no novo profissional insegurança e falta de savoir-faire para lidar com elas. Estudos já demonstraram que, na etapa inicial na docência, ocorre o fenômeno do 'choque de transição' (MARCELO, 2012; ZABALZA, 1994) ou, como querem outros autores (SILVA, 1997; HUBERMAN, 1992; VEENMAN, 1984), o 'choque de realidade', período propenso a gerar a falta de motivação (FEIMAN-NEMSER, 2001; 2003), o mal-estar (GOLD; ROTH, 1993) e, muitas vezes, o desencorajamento (DARLING-HAMMOND, 2000), que desencadeia a evasão profissional (INGERSOLL; STRONGER, 2011).

Para lidar com essas dificuldades, o espaço da residência surge como um Terceiro Espaço, conforme acima conceituado, onde o poder de autoridade do saber acadêmico como fonte de preparação para ensinar se dilui e se integra com o saber da vivência - criando formas de conhecimento menos hierárquicas e, assim, dando novas oportunidades de aprendizagem aos professores em formação. Nas palavras de Gutiérrez (2008, p. 152), é “um espaço de transformação onde o potencial para formas expandidas de aprendizagem e o desenvolvimento de novos conhecimentos se amplia".

Outro fator importante para o êxito da aprendizagem durante a residência é a oportunidade dada a processos de metacognição. Por 
meio desse exercício, o residente vai adquirindo atributos técnicos e relacionais que lhe permitem se responsabilizar progressivamente pelos atos profissionais. (BOTTI; REGO, 2010, p. 138), até que não precise mais da ajuda do preceptor.

As diferentes oportunidades de atuação e a exposição a atividades de cunhos diversos visam, ainda, a ajudar o residente a enfrentar os vários conflitos e tensões presentes em sua fase inicial de atuação docente. Beach e Pearson (1998) categorizam tais tensões e conflitos em quatro tipos. Primeiro, os conflitos curriculares e de instrução se apresentam na medida em que docentes, especialmente os em atuação inicial, se prendem a conceitos e teorias aprendidas e, por vezes, se questionam como eles se encaixam nas realidades de sala de aula ou mesmo se desestabilizam diante das divergências entre propostas pedagógicas aprendidas e a definição de qual deva ser aplicada.

Depois, há os conflitos de papel, abrangendo aqueles imanentes da sua autoimagem e de sua visão do papel que lhe cabe como professor; incluem os embates internos e as ambiguidades referentes à sua própria identidade, na transição de estudante para professor. Professores em início de carreira, ou mesmo daqueles em fase de licenciamento (ou formação inicial já com atuação em sala de aula), vivenciam problemas com a ambiguidade de estar em uma posição transitória (ou até 'bipolar') entre estudante e professor. Os participantes do estudo de Beach e Pearson (1998) ressaltaram a inquietação entre ser amigo dos alunos ou ser figura de autoridade.

O terceiro conflito, das relações interpessoais, diz respeito às relações sociais com outros agentes da comunidade escolar - alunos, professores, funcionários, administradores - e as dificuldades de conviver com as tensões com os diferentes grupos de alunos em sala de aula ou mesmo com sua própria sensação de isolamento dos demais membros da comunidade docente.

O quarto tipo de conflito é o contextual ou institucional, que surge das divergências entre as expectativas que carregam para o espaço escolar e o que, de fato, é institucionalmente permitido ou esperado que façam. Embora saiam de seus cursos de formação com a missão de ser agentes de mudança, ao se depararem com as normas e cultura do sistema escolar que atuam, enfrentam restrições e limitações que emperram sonhos e projetos educacionais.

Dentro do Programa de Residência, não só as atividades projetadas, mas também o pareamento com professores mais experientes trazem oportunidades de reflexão e de discussão de problemas, conflitos e vivências de todas as naturezas, podendo 
servir de espaço de compreensão e resolução ou mitigação de grande parte destes conflitos e tensões. Como concluem Beach e Pearson, na investigação descrita em seu trabalho de 1998, "um resultado central do estudo é o de que os participantes, ao lidarem com conflitos e tensões, questionavam e reviam suas teorias pessoais de ensino" (BEACH; PEARSON, 1998, p. 350) e, pode-se acrescentar, cresciam na sua prática pedagógica.

\section{UMA EXPERIÊNCIA EM UMA ESCOLA DE REFERÊNCIA}

Fica evidente, pelas considerações tecidas acima, que um projeto de residência bem-sucedido precisa ser plantado em solo fértil - isto é, os novos profissionais que estão se aperfeiçoando necessitam de uma ecologia favorável ao seu crescimento. Tal ecologia se traduz em um ambiente escolar estruturado, com níveis de sucesso reconhecidos, com infraestrutura compatível com projetos inovadores e tradições exitosas e - talvez acima de tudo profissionais competentes que possam transmitir, liderar, motivar e interagir na construção de novas formas de atuação.

O Colégio Pedro II (CPII) tem o reconhecimento da sociedade civil e da comunidade acadêmica e governamental por ser uma instituição com tal ecologia. Trata-se de um colégio público federal, um verdadeiro sistema educacional, composto por 14 campi situados em regiões diversas do estado do Rio de Janeiro. Nele estudam atualmente cerca de 14.000 alunos distribuídos desde os anos iniciais do Ensino Fundamental até o último ano do Ensino Médio. Seu corpo docente tem, aproximadamente, 1.000 professores com respeitável qualificação acadêmica. Pode-se garantir que a grande maioria desses professores é especialista e quase 50\% tem título de mestre ou doutor. É, sem dúvida, um colégio de excelência reconhecida e contribui fortemente na formação intelectual e no desenvolvimento da cidadania de muitas crianças e adolescentes do estado.

Ao mesmo tempo que criou o Programa de Residência Docente, o Colégio Pedro II criou o Mestrado Profissional em Práticas de Educação Básica. Desse modo, constituiu um ambiente de investigação acadêmica voltado para a prática, típico do que se concebe como Terceiro Espaço. Os alunos do Programa de Residência Docente interessam-se naturalmente por acompanhar as atividades dos alunos do mestrado e alguns deles já se candidataram e foram aprovados no processo de seleção para o mestrado profissional. 
O Projeto da Residência Docente se constitui em um de uma série de projetos que pretendem ampliar o espectro de atuação do CPII, em alguns casos, para fora dos seus limites. Neste relato pretende-se não só apresentar como se deu a implementação deste programa inovador de capacitação docente, como também incentivar outras instituições de excelência no país a adaptá-lo às suas realidades e implementar formas similares também em suas instituições, de modo a contribuirmos para o desenvolvimento da educação básica do país.

\section{O PROJETO PILOTO - PRD}

A ideia central deste Projeto, bem como a sua nomenclatura, se coaduna com a proposta do "Programa de Especialização em Licenciatura com estágio Supervisionado em regime de Residência para Recém-licenciados" proposto no âmbito do Prodocência em 2004, com objetivo de construir um programa para professores nos moldes da Residência Médica - tal programa, porém, não foi implementado à época pelo Ministério da Educação. O Programa de Residência Docente (PRD) do Colégio Pedro II surgiu a partir de reuniões entre a CAPES e o Colégio Pedro II (CPII) interessados em desenvolver projetos para contribuir com a formação complementar dos novos docentes das escolas públicas do estado e município do Rio de Janeiro. Aliou-se a possibilidade de fomento da CAPES com a disposição e inovação que o CPII poderia proporcionar para promover um programa que contribuísse com a qualificação da formação dos novos docentes dentro da conceituação de preparação para atuação profissional discutida neste artigo. Com o foco principal no desenvolvimento da autonomia, na produção e na aplicação de estratégias didáticas, na internalização de preceitos e normas éticas e no estímulo à reflexão crítica sobre a ação docente, o PRD foi concebido com o forte propósito de aliar pesquisa, teoria e prática para que o profissional recém-formado do magistério acumulasse mais subsídios para o exercício de sua docência com maior qualificação e segurança.

Vários objetivos fundamentaram a construção do projeto, dentre os quais destacam-se:

- contribuir para o aprimoramento do desempenho de docentes recém-formados no ambiente da escola pública e o aperfeiçoamento da competência profissional adquirida na graduação;

- desenvolver estratégias pedagógicas apropriadas para a realidade educacional do estado/município; 
- capacitar os participantes para que ajam como multiplicadores em seus ambientes educacionais;

- criar produtos acadêmicos relacionados à prática docente, aplicáveis à realidade da escola pública.

Com esses ideais, o Colégio Pedro II, fomentado pela CAPES por meio da concessão de bolsas a todos os seus participantes, certifica os professores Residentes que cumprirem todas as atividades previstas com o título de Especialistas em Docência do Ensino Básico na sua disciplina específica de atuação. O programa se tradur, portanto, em uma Pósgraduação (Lato-sensu), com características diferenciadas dos cursos de Especialização tradicionais, por não se ater ao oferecimento de disciplinas ou módulos em que professores ministram aulas e alunos assistem. A proposta do PRD é de engajamento e ação in situ como instrumentos de aprendizagem.

Com vistas a fazer conhecer o programa a seu público-alvo, foram estabelecidos convênios com as Secretarias de Educação do Estado e do Município do Rio de Janeiro, que divulgaram o Programa nas suas respectivas redes com suas normas e exigências e nos encaminharam os professores interessados em participar desse novo projeto como residentes - professores em processo de formação continuada. Por outro lado, professores do Colégio Pedro II foram selecionados nos diversos departamentos pedagógicos com inserção no Ensino Fundamental II e no Ensino Médio, dentro de critérios internos que valorizavam a experiência profissional de qualidade em suas diversas facetas, para que atuassem como professores supervisores, ou mentores dos residentes participantes, e coordenadores de área de ensino. Aliando os departamentos interessados com a demanda das redes públicas consultadas, o programa, no seu primeiro ano, ficou dividido em sete áreas englobando as disciplinas segundo o Quadro 1, a seguir.

\section{QUADRO 1}

Áreas do PRD-CPII no projeto piloto (2012)

\begin{tabular}{|cl|}
\hline Área & \multicolumn{1}{c|}{ Disciplinas } \\
\hline I & Matemática \\
\hline II & Biologia, Física, Química \\
\hline III & Português \\
\hline IV & Espanhol, Inglês \\
\hline V & Geografia, História \\
\hline VI & Sociologia \\
\hline VII & Educação Física \\
\hline
\end{tabular}

Fonte: Elaborado pelos autores deste artigo. 


\section{Os participantes e seus papéis}

De modo a atender a estruturação do projeto, os participantes do PRD ficaram distribuídos em quatro categorias, descritas a seguir, com as particularidades referentes a requisitos e principais funções.

Residentes Docentes: Público-alvo do programa, formado prioritariamente por professores da rede pública estadual e municipal (preferencialmente de escolas de baixo Ideb), com diploma de Licenciatura Plena e que atuem, na versão do projeto 2012, em quaisquer das disciplinas oferecidas no programa do $6^{\circ}$ ano do Ensino Fundamental ao $3^{\circ}$ ano do Ensino Médio.

Professores Supervisores: Professores integrantes do quadro efetivo de professores do CPII, com título mínimo de especialista e experiência docente mínima de três anos na Instituição. Atuam diretamente com os Residentes Docentes da sua disciplina nos seus campi de lotação, orientando, supervisionando e avaliando suas atividades no Colégio Pedro II, assim como auxiliando e orientando a organização de atividades na escola de origem do Residente.

Coordenadores de Área: Professores integrantes do quadro de professores pós-graduados do CPII, com título de mestre ou doutor e experiência docente mínima de três anos na Instituição. São professores experientes e que já comprovaram trabalhos docentes de qualidade em sala de aula e experiência em atividades acadêmicas. Responsáveis por definir, em conjunto com o Coordenador Institucional e sua equipe, as linhas-mestras do Programa, atuam com os Professores Supervisores de suas respectivas áreas definindo trabalhos, estudos e práticas a serem realizados pelos Residentes Docentes nas atividades desenvolvidas tanto dentro do CPII assim como na escola de origem de cada Residente.

Coordenador Institucional: professor integrante do quadro de professores pós-graduados do CPII, lotado na Pró-Reitoria de Pesquisa e Pós-Graduação, com o título de doutor. É o responsável pela organização geral do PRD e atua como interlocutor entre a CAPES e as Secretarias envolvidas, fornecendo-lhes dados e documentos relativos ao acompanhamento do Programa.

A estrutura do programa no que diz respeito aos participantes e órgãos envolvidos pode ser representada pelo esquema apresentado na Figura 1: 
FIGURA 1 - Interação entre participantes e agentes envolvidos no PRD

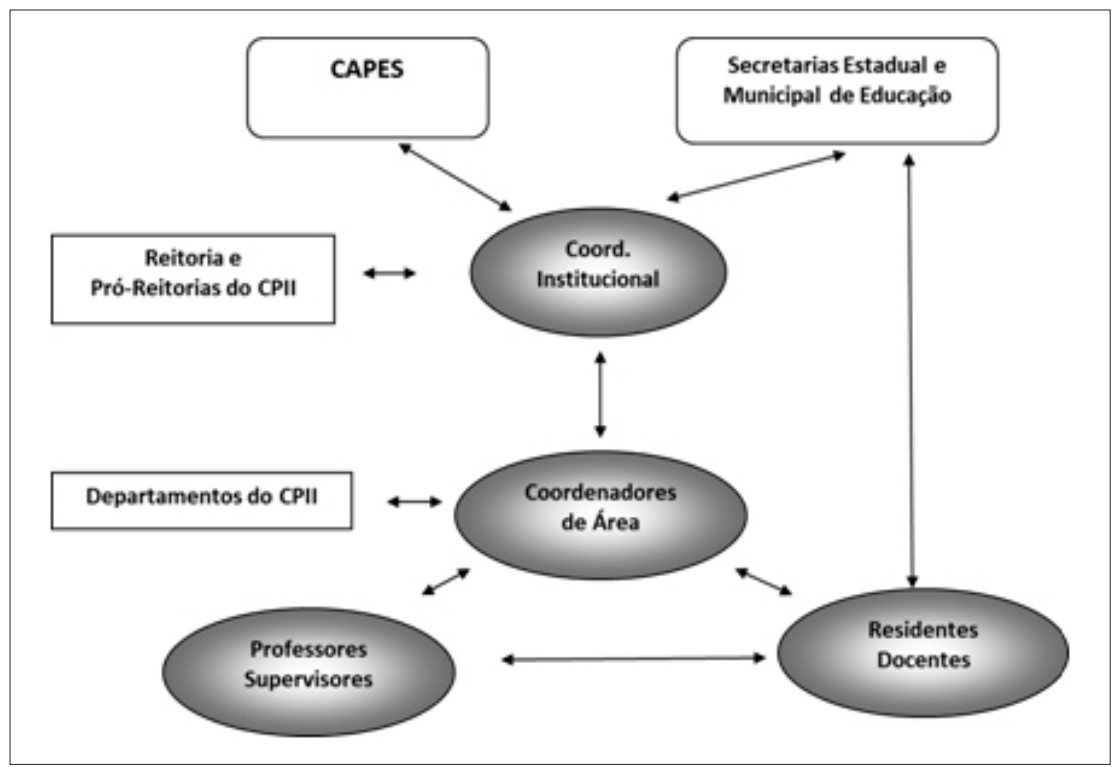

Fonte: Elaborado pelos autores deste artigo.

É importante salientar que, inicialmente, algumas linhas gerais do Programa foram traçadas em conjunto com os departamentos pedagógicos do Colégio Pedro II, incluindo a seleção dos docentes do CPII que assumiriam as funções de Coordenadores de Área e de Supervisores. O envolvimento dos departamentos se justifica pela necessidade de integração das atividades do PRD às ações regulares do dia a dia do processo de ensino-aprendizagem realizado nos diferentes campi e segmentos do sistema escolar CPII.

Em 2012, na etapa piloto, o PRD contou com 67 Residentes Docentes e 20 Supervisores nas sete áreas, além dos oito Coordenadores (sendo, como já mencionado, sete Coordenadores de Área e uma Coordenação Institucional). Coube aos Coordenadores de Área e Supervisores, sob a orientação da equipe gestora do projeto na Pró-Reitoria de Pesquisa e Pós-Graduação, definir o detalhamento dos processos organizacionais ao longo do andamento do projeto no ano letivo.

\section{As atividades do projeto}

O PRD, embora tenha sido elaborado com alicerces fincados e uma estrutura bem definida, é um projeto em constante construção, de modo a atender a demanda por melhorias na qualidade da educação brasileira. Apoiado no tripé teoria, pesquisa e experiência prática, o projeto piloto tomou forma e consolida-se com a formação de novas turmas. 
A carga horária total, distribuída no período de um ano letivo em atividades presenciais e à distância, bem como as atividades desenvolvidas na própria escola onde o Residente está em exercício, constroem os campos de ação nos quais os professores residentes atuam. É no próprio espaço escolar do professor residente, ou em função dele, que acontece uma parte significativa da ação de formação, de modo a tornar mais efetiva a ação do residente nos moldes da residência médica, vinculando-o à realidade para a qual precisa se equipar.

Procurando proporcionar ao Residente uma formação abrangente, e com a certeza de que todos os segmentos de uma escola de excelência contribuem para o objetivo final, é oferecida ao Residente a possibilidade de observar, participar e interagir em setores diversos da estrutura escolar, tais como Biblioteca, Setor de Orientação Pedagógica, Secretaria Escolar, Setor de Recursos ao Apoio Escolar (para alunos com necessidades específicas), dentre outros. Assim, qualifica-se o residente não só em atividades inerentes a sua área do conhecimento, e à prática pedagógica em si, mas também em toda a estrutura que perfaz uma escola - o que vem a se somar aos subsídios para uma prática profissional reflexiva com orientação para adaptar os conhecimentos obtidos à realidade da sua sala de aula.

Com essa visão, o programa teve suas horas divididas em três grupos de atividades a serem desenvolvidas pelos Residentes, representadas na Figura 2, áreas que se complementam e interagem uma vez que se preocupam com três áreas básicas do conhecimento para qualificação docente: conhecimento do aluno, conhecimento do assunto, conhecimento do ensino (SHULMAN, 1987; VEAL; MAKINSTER, 1999; TARDIF; RAYMOND, 2000).

FIGURA 2 - Distribuição de atividades dos residentes no PRD

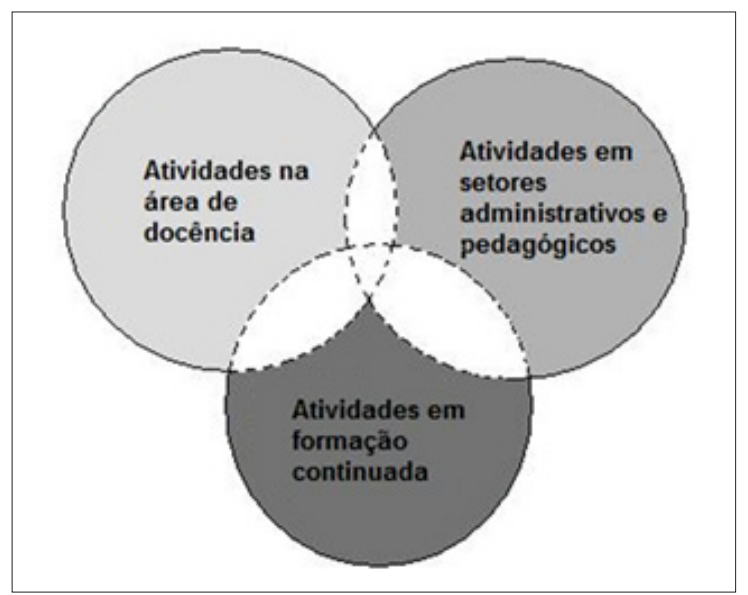

Fonte: Elaborado pelos autores deste artigo. 
A seguir, são descritos os tipos e variedade de ações e atividades contempladas em cada área.

Atividades na área de docência: (que correspondem a 65\% da carga horária do programa).

Observar, colaborar e ministrar aulas da sua disciplina ou outra de área afim com a presença de um docente do Colégio Pedro II; participar de projetos desenvolvidos pela escola e atividades complementares; elaborar plano de aula; orientar estudos dirigidos com grupos de alunos; participar de visitação técnica e/ou cultural com os alunos; preparar material didático com o olhar também nos alunos com necessidades especiais; participar de reflexões sobre avaliação de livros e provas de concursos da sua disciplina; participar de reuniões pedagógicas; preparar e aplicar atividades pedagógicas na sua escola de origem, a partir de pressupostos oriundos das atividades desenvolvidas no CP II; elaborar relatórios periódicos sobre as atividades aplicadas na sua instituição, anexando fotos, material utilizado, etc.; avaliar junto com o Professor Supervisor as atividades desenvolvidas na sua escola; elaborar e apresentar um produto acadêmico-pedagógico relacionado à prática docente, chamado de Produto Final, sob a orientação do seu Professor Supervisor, a ser avaliado por uma comissão do Programa.

\section{Atividades em setores administrativo-pedagógicos do CPII (abrangem cerca de 10\% da carga horária do programa). \\ Conhecer a forma de atuar, a organização e os objetivos do SESOP (Setor de Supervisão e Orientação Pedagógica), da biblioteca escolar, da secretaria, do laboratório de informática a fim de entender a importância do bom funcionamento desses setores na vida acadêmica e pessoal do aluno.}

Atividades em formação continuada: (somam cerca de $25 \%$ da carga horária do programa)

Participar de oficinas, palestras, minicursos, congressos e eventos presenciais e/ou semipresenciais de natureza acadêmica; elaborar, ao final do primeiro semestre letivo, um relatório das atividades desenvolvidas; elaborar, ao final do ano letivo, um Memorial Circunstanciado de sua trajetória no Programa de Residência Docente, incluindo não só as atividades desenvolvidas, mas também avaliação e reflexão crítica destacando os pontos positivos da sua experiência, as sugestões de aperfeiçoamento do Programa, as áreas em que sentiu crescimento profissional e as contribuições específicas à sua futura prática profissional. 
Cabe ressaltar que a maioria das oficinas oferecidas aos Residentes, incluídas no grupo de atividades de formação continuada acima descrito, foram ministradas por docentes do Colégio Pedro II em geral que se qualificavam para esse encargo, sendo algumas delas desenvolvidas por professores externos convidados. Além de oficinas oferecidas com temas específicos das disciplinas, que visam ao aprimoramento do conhecimento de conteúdo a ser ensinado, ou seja, 'o que ensinar', nos termos de Schulman (1987), foi promovida uma série de oficinas de temas transversais da Educação, pertinentes a Residentes de todas as áreas, que, além de incentivar a reflexão sobre a sua prática, sobre o seu aluno e sobre os processos educacionais de uma forma geral, permitiram integração e troca de experiências entre os Residentes das diversas áreas do programa. Nessas oficinas, enfatizavam-se as perspectivas de Schulman (o 'como ensinar' e 'a quem ensinamos', além de se permitir a reflexão do 'porquê de ensinar o que se impõe, curricularmente, ensinar').

A distribuição das 500 horas do Programa, tanto no que se refere à organização das atividades de cada uma das três áreas, como no que diz respeito às horas de disponibilidade e local de atuação dos Residentes, foi planejada de modo que houvesse um arranjo equilibrado e diversificado de atividades ao longo do ano letivo. Levou-se em conta que o total das horas contempla atuação nos espaços físicos do CPII, mas também na instituição onde trabalha o residente e, ainda, o engajamento em atividades semipresenciais. $\mathrm{O}$ residente atua em, pelo menos, dois turnos semanais em atividades docentes e administrativopedagógicas dentro do CPII e disponibiliza um turno para atividades relacionadas à formação continuada, oficinas palestras, etc.

É essencial salientar que a residência ocupa cerca de 100 horas em atividades na instituição de origem do professor residente, para aplicação obrigatória de projetos desenvolvidos no âmbito do PRD. Sem essa ponte explícita com a regência na sua instituição de origem, o projeto de residência, tal como concebido, não cumpriria sua meta. $\mathrm{Na}$ aplicação do saber adquirido no PRD em sua própria sala de aula, o residente tem a oportunidade de experimentar, avaliar e reformular concepções, exercícios e processos - viabilizando o seu desenvolvimento como docente e atualizando sua prática. Para maior eficácia nessas ações, o residente conta com a orientação de seu professor supervisor no PRD, com quem também partilha os momentos de avaliação do que foi realizado. 


\section{As estratégias para aferir resultados}

A avaliação dos resultados obtidos no processo de desenvolvimento profissional ou em projetos que visam ao aprimoramento de ações e ampliação de conhecimentos é, consensualmente, parte integrante de qualquer proposta, a fim de que se possa medir os efeitos e resultados da intervenção. No PRD, foram concebidos três eventos (no sentido amplo do termo) com o objetivo de acompanhar e registrar as atividades desenvolvidas pelos Residentes nas diversas áreas, avaliar o impacto do projeto no incremento da formação do professor Residente, obter a visão deste professor sobre o conjunto do programa e aperfeiçoar o próprio Programa para a versão 2013. Tais trabalhos fornecem dados avaliativos, tanto da evolução e do resultado alcançados pelos residentes ao longo e ao final do programa, quanto do transcurso e efeitos oriundos do programa como uma forma de intervenção na preparação de docentes da Educação Básica. As estratégias de avaliação engendradas trazem a visão do residente e são submetidas à apreciação de supervisores, coordenadores de área e equipe gestora do projeto na Pró-Reitoria de Pesquisa e Pós-Graduação. Nessa apreciação, torna-se possível atender às orientações de Patton (2008, p. 39) no sentido de empreender o exame das atividades do programa e seus resultados a fim de fornecer informações sobre os efeitos do programa, tanto os intencionais quanto os não intencionais, para reduzir as incertezas, melhorar a eficácia do programa e dar elementos para tomada de decisões.

Os três instrumentos formais de avaliação que compõem o PRD são: o Relatório Semestral, o Memorial Circunstanciado e o Produto Final e estão descritos a seguir. Neste trabalho utilizamos dados obtidos a partir desses instrumentos para ressaltar as características do Programa de Residência Docente do Colégio Pedro II, como Terceiro Espaço na formação continuada de professores, no sentido atribuído por Zeichner (2010), identificando ainda as tensões e os conflitos dos professores recém-formados que aparecem na fase de transição aluno-professor, segundo Beach e Pearson (1998).

\section{a) Relatório Semestral}

Trata-se de um relato sobre a trajetória do Residente no PRD, incluindo as atividades por ele desenvolvidas no CPII e na sua escola de origem, no primeiro semestre letivo. Conferido e avaliado pelo Professor Supervisor e referendado pelo Coordenador de Área, serve de base para a posterior construção do Memorial Circunstanciado. 


\section{b) Memorial Circunstanciado}

Este relatório compõe-se de um relato sobre toda a trajetória do Residente no PRD, incluindo não só as atividades desenvolvidas (como no Relatório Semestral), mas também avaliação e reflexão crítica aprofundada, destacando os pontos positivos da sua experiência, as sugestões de melhoria para o programa, as áreas em que sentiu crescimento profissional e as contribuições específicas à sua futura prática profissional. É importante que inclua também uma reflexão sobre o seu Diário Reflexivo - instrumento de registro de atividades com apreciação crítica que foi apresentado aos residentes em uma das oficinas iniciais oferecidas, na qual todos os residentes deveriam se inscrever. Espera-se que, ao mencionar o Diário Reflexivo, o residente destaque como ele serviu para o acompanhamento e a avaliação do seu processo de desenvolvimento durante a Residência. Documentos comprobatórios assim como fotos, materiais confeccionados e/ou utilizados nas suas ações docentes no CPII ou na escola de origem devem ser anexados, compondo um portfólio de trabalhos realizados, para que seja possível uma melhor avaliação conjunta dessa trajetória pelo Supervisor e pelo Coordenador.

Dos memoriais extraímos fragmentos com impressões dos residentes sobre a experiência no PRD. Encontramos neles expressões que revelam a angústia gerada pelos conflitos e tensões próprios do início da carreira docente como descrevem Beach e Pearson (1998), identificando-se quatro categorias de conflito: currículo e instrução, relações interpessoais, contextual e institucional e sobre o papel a exercer. Dos relatos apresentados nos diversos memoriais destacamos alguns que indicam a possibilidade de esses conflitos serem minimizados ou resolvidos, ao acrescentarmos a constituição do conceito de Terceiro Espaço, no sentido atribuído por Zeichner (2010), como local extensivo da formação, estabelecendo interfaces entre meio acadêmico e realidade escolar, experiência concreta e formulação teórica, e entre conceituação e vivência prática.

Muito foi dito e muito eu ainda tinha a dizer. Certamente, todas as experiências vivenciadas e os ensinamentos aprendidos neste Programa de Residência não caberia, mesmo na escrita de um memorial. Há aprendizados que têm natureza imaterializável, indizível, embora tenhamos certeza da sua existência e força em nossas vidas.

Findar mais uma etapa do Programa, significa, para mim, iniciar uma nova etapa na caminhada da profissão docente não mais com as mesmas perspectivas. Cada vez mais, vejo um horizonte mais desmedido de possibilidades na área da Educação, acreditando ser realizável no magistério a aplicação dos conceitos contemplados no Programa de Residência Docente, dado o diálogo estabelecido 
com a atuação prática da profissão docente. Na referida Formação Continuada, encontrei o norte de que precisava para orientar minhas reflexões, já iniciadas, a respeito da prática docente. Assim também como a troca de experiências com os colegas residentes e as orientações dos mestres do CPII foram essenciais para acrescentar conhecimento (teórico e prático) aos meus, ainda, tão principiantes cinco anos de atuação no magistério.

Estando agora muito próximo do final do Programa, faltando apenas a elaboração do Produto Final Acadêmico, sustento em mim intenções ousadas, por vezes agigantadas, de multiplicar o aprendizado obtido no Programa de Residência com os demais colegas de profissão que, assim como eu, principalmente nos anos iniciais de prática docente, também compartilham da sensação de que falta "algo mais"; talvez, experiência, segurança, conhecimento pragmático do dia a dia da profissão; enfim, necessidades de que os cursos de formação de professores não dão conta, plenamente. (Aluno X, residente 2012, escola municipal)

Observando o relato do Aluno X, identificamos plenamente o que Beach e Pearson (1998) relatam em seus estudos e que certamente fizeram o Aluno X buscar o PRD. É explícita a angústia relacionada ao currículo e à instrução e a conceitos e teorias aprendidas na formação inicial e que, por vezes, não se encaixam nas realidades de sala de aula. Observamos a busca pelo verdadeiro papel do professor no percurso de uma formação sólida.

O PRD - Programa de Residência Docente - no qual estive durante o ano de 2012 e início de 2013 foi amplamente significativo na minha vida profissional, pois o trabalho de grande qualidade educacional exercido pelos professores do Colégio Pedro II é o mesmo que direciona nossa reflexão e desenvolvimento profissional. A essa conclusão eu já havia chegado no fim do primeiro semestre do programa, no entanto, agora, ao final, eu posso dizer mais: o Programa é necessário, porque muitos dos professores jovens têm dúvidas, medos e inseguranças a serem trabalhadas e esse programa em forma de especialização voltado em sua maioria para a prática e para a reflexão da prática foi essencial no meu desenvolvimento como professora, porque através das aulas observadas, dos trabalhos feitos, das oficinas, das reuniões com professores experientes, entre outras atividades, pude ver mais claramente os caminhos a percorrer para contribuir mais e melhor com o processo de ensino-aprendizagem dos alunos que tenho e os que terei ao longo de toda a carreira que tenho pela frente, nunca deixando de lado a parte afetiva da profissão e a consciência de que a dedicação faz parte do caminho, logo, é preciso estar inteiro nesta estrada. Termino, então, este memorial, de forma imensamente agradecida aos pensadores e colaboradores do programa do qual tive orgulho de participar [...] (Aluno Y, residente 2012, escola municipal)

$\mathrm{Na}$ fala do Aluno $\mathrm{Y}$ encontramos em poucas palavras a síntese das categorias de que falam Beach e Pearson (1998) quando explicitamente diz: "[...] muitos dos professores jovens têm dúvidas, medos e inseguranças a serem trabalhadas [...]". Certamente Y fala das relações interpessoais, do papel a exercer, do conflito curricular e de instrução e da relação contextual e institucional. 
Satisfação! Talvez esta seja a melhor palavra para resumir minha sensação ao concluir o Programa de Residência Docente. Superou em muito minhas expectativas. Qualquer um que faça uma pós-graduação espera um acréscimo em sua formação, mas não imaginei que o nível de aproveitamento seria tamanho.

As oficinas, palestras e seminários agregaram um grande valor a minha formação e propuseram grande reflexão a respeito de minha prática pedagógica. Certamente sou outro profissional após a formação. As observações das aulas também muito contribuíram, trazendo sugestões e instigando-me a tentar ir além nas "minhas" aulas.

Dessa forma, creio que o Programa de Residência Docente é uma completa pós-graduação em todos os aspectos possíveis, proporcionando-me o que há de melhor para ser complementado e aperfeiçoado em minha formação. (Aluno Z, residente 2013, escola estadual)

O Aluno Z, ao mencionar o modo como o PRD influenciou sua formação, constata que professores recém-formados buscam o preenchimento de lacunas deixadas pela formação inicial que os colocam em conflitos relacionados à atuação em sala de aula e à carreira.

Gostaria de parabenizar e agradecer a todos, Coordenadores, Supervisores, Mestres e Doutores, que no decorrer da minha caminhada ajudaram-me na confecção deste Memorial. Este programa proporcionou um crescimento na minha vida profissional e educacional. Projetos como esse deveriam ser seguidos por outras instituições, pois colabora de uma forma direta para uma interação e uma união, entre educador e educando. Ao terminar esse programa, sinto que dei um grande passo na compreensão e responsabilidade que tenho, diante da educação. Buscar novas metodologias e tecnologias para uma melhora do ensino aprendizagem é dever de todo professor educador. (Aluno W, residente 2013, escola estadual)

Ao identificar as categorias de Beach e Pearson (1998) nos fragmentos destacados acima encontramos as angústias e tensões dos primeiros anos de prática profissional, ao mesmo tempo que podemos fazer uma leitura da forma como esses docentes buscam resolver tais conflitos. Encontramos respaldo no conceito de Terceiro Espaço de Zeichner (2010) para reconhecer nas falas a busca para uma melhor construção da sua carreira profissional.

A convicção alcançada pelo Aluno X de que é "realizável no magistério a aplicação dos conceitos contemplados no Programa de Residência Docente, dado o diálogo estabelecido com a atuação prática da profissão docente" traduz de forma clara ter o Programa atingido o que se propõe, isto é, como uma realização do Terceiro Espaço na área de Educação, constituir um modelo de formação continuada e capacitação em serviço. O residente demonstra ter vivenciado a integração das questões conceituais ao desenvolvimento de soluções específicas para os contextos de sua atuação profissional, por meio do desenvolvimento de construtos didáticos que se aliam aos conceitos disciplinares. Isso possibilita 
desenvolver no educador, como demonstrado pelo Aluno X, uma visão crítica da realidade escolar e das necessidades dos agentes do processo ensino-aprendizagem. A experiência vivida em situação escolar diferente da que é própria do residente, em conjunto com o compartilhamento de ações docentes com pares mais experientes, traz novas ideias e perspectivas diferenciadas.

Observando o segundo relato acima (do Aluno Y), mais uma vez constatamos como o programa lhe tornou possível, "através das aulas observadas, dos trabalhos feitos, das oficinas, das reuniões com professores experientes, entre outras atividades [...] ver mais claramente os caminhos a percorrer para contribuir mais e melhor com o processo de ensino-aprendizagem dos alunos que tenho e os que terei ao longo de toda a carreira que tenho pela frente". Ao oferecer parceria com docentes mais experientes durante vivências escolares e compartilhamento de ações docentes e criar variados espaços de reflexão, ação, criação e autoavaliação, o PRD lhe deu condições para entrelaçar fundamentação teórica e aplicação em contexto educacional. Esse relato demonstra ainda como o Programa instiga posturas investigativas e confiança na mudança de atitude, que o tornam um profissional socio-historicamente contextualizado e adequado a uma educação eficaz. O relato demonstra assim que o Programa de Residência Docente atinge seu objetivo, isto é, de proporciona ao professor iniciante condições de segurança para seguir adiante.

No terceiro depoimento, de professor de escola estadual, mais uma vez observamos o Programa de Residência Docente desenvolver no educador uma visão crítica da realidade escolar e das necessidades dos agentes do processo ensino-aprendizagem, compreendendo, analisando e elaborando respostas criativas aos nós de aprendizagem. A experiência vivida em situação escolar diferente da que é própria do residente, em conjunto com o compartilhamento de ações docentes com pares mais experientes, traz novas ideias e perspectivas diferenciadas. É o que registra em seu relato de que "as oficinas, palestras e seminários agregaram um grande valor a minha formação e propuseram grande reflexão a respeito de minha prática pedagógica." O mesmo confirma sua afirmação de que "certamente sou outro profissional após a formação".

O último relato transcrito destaca o pilar da pesquisa na estrutura do Terceiro Espaço baseada na interação sobre os pilares da teoria, da prática e da pesquisa. O residente destaca: "ao terminar esse programa, sinto que dei um grande passo na compreensão e responsabilidade que tenho, diante da educação. Buscar novas metodologias e tecnologias para uma melhora do ensino aprendizagem é dever de todo professor 
educador". Quando propomos ao residente parceria com docentes mais experientes durante vivências escolares e compartilhamento de ações docentes e criação de variados espaços de reflexão, ação, criação e autoavaliação, vemos, como apontam Tardif e Raymond (2000), que os diversos saberes dos professores estão longe de serem produzidos por eles, de fato, há uma rede que entrelaça fontes sociais de aquisição com modos de integração no trabalho docente.

\section{c) Produto Final}

De natureza acadêmico-pedagógica, o produto final está relacionado à prática docente no Ensino Fundamental e/ou Médio. Além de um produto pedagógico em si, acompanha uma monografia que o contextualiza. A formatação desse trabalho escrito inclui uma parte introdutória, situando a motivação do produto, o público-alvo e os pré-requisitos (se houver). Seguem-se a justificativa e os objetivos do desenvolvimento do produto e a descrição da metodologia didáticopedagógica que o fundamenta, a partir de embasamento teórico. Um dos requisitos importantes é a aplicação do produto pedagógico efetivamente na instituição de origem do Residente durante o PRD, incluindo relato da aplicação e uma apreciação avaliativa de sua adequabilidade, eficácia e alcance das expectativas delineadas.

O produto pedagógico de cada residente é submetido à avaliação de uma banca de três professores, constituída de um professor participante do Programa (Supervisor ou Coordenador de Área) da área do Residente e dois professores participantes oriundos de outras áreas disciplinares. As apresentações dos Produtos Finais são realizadas em sessão pública, de modo a viabilizar a socialização dos produtos entre todos os participantes e demais interessados.

À guisa de exemplificação, listamos aqui alguns poucos exemplos, de áreas variadas, que ilustram os tipos de produtos elaborados: Uma proposta para o aprendizado de conceitos elementares de matemática do Ensino Básico utilizando o software Geogebra (BORGES, 2013); O uso do blog nas aulas de educação física escolar (CARVALHO, 2013); Os usos da literatura no ensino de história: uma perspectiva comparativa entre duas práticas pedagógicas diferenciadas (MAINOTH, 2013); Arvore genealógica: pesquisando novas origens étnicas e eliminando o racismo na escola (CORREIA, 2013); e Jogo de tabuleiro: Protetores da natureza (GESTEIRA, 2013). ${ }^{1}$

Os vários produtos pedagógicos apresentados revelaram riqueza da experiência que os residentes tiveram durante o Programa. É evidente que os professores residentes se apropriam de visões teóricas, técnicas pedagógicas e estratégias didáticas que não conheciam anteriormente, ou que não sabiam ou hesitavam em aplicar, e ainda 
são estimulados a adaptar, criar ou integrar novas formas de ensino ou orientação à aprendizagem de seus alunos.

O professor supervisor, orientador desse produto, objetiva uma prática reflexiva e faz o papel do "estimulador de mudanças didáticas" segundo descrição de Garrido e Carvalho (1999). O trabalho é elaborado a partir de pesquisas bibliográficas e com fundamentação teórica bem sedimentada e representa a culminância do projeto, procurando desenvolver muito além do que um produto aplicado, mas um produto aplicado que sintetize o embasamento teórico, o cotidiano vivenciado, a segurança adquirida, a criatividade estimulada e a motivação docente, trabalhados durante o ano letivo com esse jovem professor em prol de seus alunos.

Muitos trabalhos refletem questões interdisciplinares, utilizam tecnologia da informação e da comunicação, constroem material didático inédito e são disponibilizados para novas aplicações e/ ou adaptações por outros professores das escolas dos residentes, constatando o efeito multiplicador do programa.

Reflexões apoiadas em Schulman (1987) sobre "o que ensinar", "como ensinar", "a quem ensinar" e "por que ensinar" estão presentes nesses produtos que expõem, de forma clara e em sintonia, os alicerces do programa: teoria, pesquisa e prática aplicando as bases do Terceiro Espaço na integração dos saberes acadêmicos e experimentais (Zeichner, 2010).

\section{EXPECTATIVAS E AJUSTES}

O sucesso obtido com o Projeto Piloto do PRD-2012 no Colégio Pedro II levou a uma implementação mais abrangente do Programa, em 2013. Com a experiência acumulada em 2012, o PRD-2013 teve por meta dar continuidade ao processo de construção de estratégias de ensino mais democráticas e eficientes e aperfeiçoar as experiências desenvolvidas no âmbito do Programa, a fim de oferecer oportunidades de crescimento profissional e de qualificação ao Professor Residente.

Em função dos resultados e do impacto do Programa, foi possível negociar com a CAPES uma ampliação em torno de $80 \%$ do número de vagas oferecidas para os Professores Residentes em relação ao PRD-2012. Essa alteração respondeu à análise realizada em torno dos efeitos do PRD-2012, dentro dos parâmetros delineados por Antheil e Casper (1986), ou seja, verificando-se quatro níveis de efeitos do programa: a reação dos participantes, o que os participantes aprenderam, a capacidade de transferir conhecimentos para sua 
prática e o impacto na organização do programa. É possível afirmar, pelos retornos recebidos de todos os segmentos de participantes, da agência financiadora, do CPII como um todo e, especialmente, na mudança de postura em relação à docência que foi observada nos residentes, a partir de suas narrativas nos Memoriais Circunstanciados, que os resultados foram muito positivos nos quatro níveis.

Para atendermos ao novo escopo que o Programa assumiria nessa nova versão, vários ajustes foram incorporados, sendo o mais importante deles o fato de abrirmos o leque de disciplinas contempladas nas áreas existentes no Programa, ou seja, incluindo as disciplinas de Francês, Filosofia, Artes Visuais, Desenho e Música, que não haviam sido contempladas no PRD-2012, e criar mais uma área no programa com o intuito de abarcar os docentes dos anos iniciais do Ensino Fundamental. Constatou-se que há uma fatia de docentes dos anos iniciais ávidos por programas efetivos de qualificação com todas as especificidades dessa fase escolar. O Colégio Pedro II, que abriu suas portas para as crianças dessa faixa etária, a partir dos seis anos, na década de 1980, tem realizado um trabalho de ponta nessa etapa escolar, que tem resultado em índices de grande sucesso nas ações de letramento e tem muito a compartilhar de sua experiência e conquistas pedagógicas. Os professores do Colégio deste segmento também estavam motivados a participar do programa e acorreram às chamadas específicas de seleção de Professor Supervisor e Coordenador de Área.

A nova área, VIII, é certamente complexa e híbrida. Ela abrange o ciclo inicial do ensino fundamental, em que estão contempladas as habilidades de letramento em língua portuguesa e matemática, iniciação às ciências naturais e sociais, bem como as expressões artísticas e físicas. Pelo fato de lidar com processos voltados para a fase inicial da escolarização e da maturação cognitiva, os aspectos pedagógicos da aprendizagem da criança pequena trazem questões específicas que precisam ser atendidas pelos que têm formação própria para tal. E os professores do CPII que atuam nesse ciclo são qualificados, não só por sua experiência coletiva, como também por suas titulações grande parte tem Mestrado e outros, também o Doutorado.

Além dessas mudanças, também foram inseridas outras, de natureza acadêmica ou organizacional. Em função da ampliação de professores residentes que participariam, houve a preocupação de garantir o funcionamento adequado do programa sem atravancar os processos educacionais das unidades escolares que os recebessem. Assim, buscou-se distribuir os Professores Residentes de forma homogênea nos diversos campi do Colégio Pedro II, com o intuito de obter uma maior abrangência geográfica, gerando mais oportunidades 
para novos integrantes do programa - tanto Residentes quanto Supervisores, além de possibilitar olhares e saberes diversificados dos profissionais atuantes em todos os campi.

Também foi necessário adequar a distribuição das atividades constantes do Programa, de modo a atender melhor as necessidades do público-alvo (preferencialmente professores oriundos de escolas das redes públicas estadual e municipal de baixo Ideb, recémformados), a partir da experiência da versão piloto do PRD-2012. Algumas das diferenças que foram introduzidas refletem sugestões ou comentários expressos pelos participantes da versão piloto, uma das quais diz respeito à redução de carga horária total do Programa para 420 horas, de modo a tornar viável seu cumprimento dentro do ano letivo, em função do acúmulo de ações que os Residentes precisam cumprir. Por entender-se que essa alteração não afeta o resultado final e os objetivos do Programa, ajustou-se a distribuição das ações, buscando manter a ênfase nas atividades acadêmico-pedagógicas e limitando a exposição aos setores administrativo-pedagógicos.

A seleção de residentes para o PRD-2013 contou com uma chamada pública por edital, de modo a criar possibilidade para atendimento maior e mais diversificado dos Professores Residentes, na medida em que facilitava a divulgação entre os professores das redes estadual e municipal. Como não era mais um programa desconhecido, muitos dos interessados procuravam diretamente o CPII, sem terem as Secretarias de Educação como intermediárias.

\section{CONCLUSÃO}

O modelo de formação continuada e capacitação em serviço do Programa de Residência Docente do Colégio Pedro II constitui uma realização do Terceiro Espaço na área de Educação. Ele propõe mais do que a articulação teórico-prática, pois objetiva a integração das questões conceituais de práticas pedagógicas ao desenvolvimento de soluções específicas nos contextos de atuação dos residentes, através do desenvolvimento cognoscitivo de princípios e construtos didáticos que se aliem aos conceitos disciplinares. Assim, possibilita desenvolver no educador uma visão crítica da realidade escolar e das necessidades dos agentes do processo ensino-aprendizagem, compreendendo, analisando e elaborando respostas criativas aos nós de aprendizagem. A experiência vivida em situação escolar diferente da que é própria do residente, em conjunto com o compartilhamento de ações docentes com pares mais experientes, traz novas ideias 
e perspectivas diferenciadas uma vez que viabiliza um espaço que permite constante reflexão, ação, criação e avaliação dos reais conflitos vivenciados pelos professores residentes na sua prática docente. As ações do PRD, tais como reuniões com seus pares, participações em oficinas, elaborações de planejamentos e avaliações conjuntas, construções de projetos interdisciplinares, propiciam ao professor residente uma prática com suporte teórico de pares mais experientes acadêmica e profissionalmente. A imersão de residentes nos grupos de pesquisa do Mestrado Profissional em Práticas de Educação Básica do Colégio Pedro II propicia um ambiente de investigação acadêmica voltado para prática típica do que se concebe como Terceiro Espaço.

A parceria com docentes mais experientes durante vivências escolares e compartilhamento de ações docentes oportuniza condições de desenvolver no Professor Residente o espírito crítico, a experimentação pedagógica, e o entrosamento entre a fundamentação teórica e aplicabilidade em contexto educacional; instiga posturas investigativas e a confiança na transformação das atitudes reprodutoras irrefletidas em ações resultantes de reflexão sistematizada e fundamentada, que se tornam basilares para o fazer profissional socio-historicamente contextualizado e adequado a uma educação eficaz. A estrutura montada, com atividades na área de docência, de setores administrativo-pedagógicos e de formação continuada, viabiliza a integração dos saberes heterogêneos e plurais, equacionando os saberes das disciplinas, dos saberes curriculares, dos saberes da formação profissional e dos saberes da experiência. A experiência no espaço escolar do Colégio Pedro II ecoa, não como modelo a ser imitado e implantado, mas como um conjunto de vivências, experimentações e observações que podem gerar uma postura crítica e o amadurecimento para identificar e selecionar aquilo que o Residente pode incorporar em sua própria experiência de vida como professor, para enfrentar os desafios do seu dia a dia e assim criar um estilo próprio de fazer docente que leve a maiores índices de sucesso no processo ensino-aprendizagem.

\section{Agradecimentos}

A versão inicial deste artigo contou com inestimável colaboração da professora Silvia Becker (†13-12-2014), que atuou desde a concepção e a elaboração do projeto até a implementação do Programa de Residência Docente do Colégio Pedro II e foi, sempre, uma entusiasta do projeto, do Programa e deste trabalho que aqui apresentamos. 


\section{REFERÊNCIAS}

ANTHEIL, J. H.; CASPER, I. G. Comprehensive Evaluation Model: a tool for the evaluation of nontraditional educational programs. Innovative Higher Education, vol.11, n. 1, Fall/Winter 1986.

BEACH, R.; PEARSON, D. Changes in preservice teachers' perceptions of conflicts and tensions. Teaching \& Teacher Education, Cidade, v. 14, n. 3, p. 337-351, 1998.

BHABBA, H. K. (Ed). National and Narration. London: Routledge, 1990.

The Location of Culture. London: Routledge, 1994.

BORGES, A. C. Uma proposta para o aprendizado de conceitos elementares de matemática do ensino básico utilizando o software Geogebra. 37 p. Monografia Especialização em Residência Docente - Departamento de Matemática, Colégio Pedro II. Rio de Janeiro, 2013.

BOTTI, S. H. O.; REGO, S. Processo ensino-aprendizagem na residência médica Revista Brasileira de Educaşão Médica, Rio de Janeiro, v. 34, n. 1, 2010.

BRASIL. O Plano de Desenvolvimento da Educação: razões, princípios e programas. Brasilia, DF: MEC, 2007. Disponível em <http://portal.mec.gov.br/arquivos/livro/>. Acesso em 23 jul. 2013.

Resolução CFE/CP 2/2002. Institui Diretrizes Curriculares Nacionais para a Formação de Professores da Educação Básica, em nível superior, curso de licenciatura, de graduação plena. Diário Oficial da República Federativa do Brasil, Brasília, 4 mar. 2002. Seção 1, p. 9.

BULLOUGH, R et al. Long-term PDS development in research universities and the clinicalization of teacher education. Journal of Teacher Education, Washington, n.48, v. 2, p. 85-95, 1997.

BULLOUGH, R. et al. Moving beyond collusion: clinical faculty and university/public school partnership. Teaching and Teacher Education, Atlanta, v. 20, p. 505-521, 2004.

CARVALHO, A. F. P. O uso do blog nas aulas de educação física escolar. 22 p. Monografia (Especialização em Residência Docente) - Departamento de Educação Física, Colégio Pedro II. Rio de Janeiro, 2013.

CLIFFORD, G. J.; GUTHRIE, J. W. Ed school: a brief for professional education. Chicago: University of Chicago Press, 1998.

CORNBLETH, C.; ELLSWORTH, J.; Teachers in teacher education: clinical faculty roles and relationships. American Educational Research Journal, Washington, n. 1, v. 31, p. 49-70, 1994.

CORREA, R. A. Árvore genealógica: pesquisando nossas origens étnicas e eliminando o racismo na escola. 57 p. Monografia (Especialização em Residência Docente) - Departamento de História, Colégio Pedro II. Rio de Janeiro, 2013.

DARLING-HAMMOND, L. Teacher education and the American future. Journal of Teacher Education, v. 61, n.1-2, p. 35-47, 2010

Solving the Dilemmas of Teacher Supply, Demand, and Standards: how we can ensure a competent, caring, and qualified teacher for every child. National Commission on Teaching \& America's Future, 2000.

FEIMAN-NEMSER, S. What new teachers need to learn. Educational Leadership, Chicago, v.60, n.8, p. 25-29, 2003.

From preparation to practice: Designing a continuum to strengthen and sustain teaching. Teachers College Record, Ann Arbor, v.103, n.6, p. 1013-1055, 2001.

GALLAS, K.; LOOK, K. I'm running like jello: imagination as a question, a topic, a tool for literacy research and learning. In: BALLANGER, C. (Ed.), Regarding children's words: teacher research on language and literacy. New York: Teachers College Press, 2004. p. 119-148. 
GARRIDO, E.; CARVALHO, A. M. P. de; Reflexões sobre a Prática e Qualificação da Formação Inicial Docente. Cadernos de Pesquisa, São Paulo, v. 107, jul. 1999.

GESTEIRA, V. S. Jogo de tabuleiro: protetores da natureza. 24 p. Monografia (Especialização em Residência Docente) - Departamento de Biologia, Colégio Pedro II. Rio de Janeiro, 2013. GOLD, Y.; ROTH, R. A. Teachers managing stress and preventing burn-out: the professional health solution. London: Falmer Press, 1993.

GOODLAD, J. Teachers for our nation's schools. San Francisco: Jossey Bass, 1990.

GUTIÉRREZ, K. Developing sociocultural literacy in the third space. Reading Research Quarterly, Hoboken, n.43, v.2, p. 148-164, 2008.

HUBERMAN, M. O Ciclo de vida profissional dos professores. In: NÓVOA, A. (Org.). Vidas de professores. 2. ed. Portugal: Porto Editora, p. 31-61, 1992.

INGERSOLL, R. M.; STRONGER. M.; The Impact of Induction and Mentoring Programs for Beginning Teachers. Review Of Educational Research, Washington, v. 81, n.2, p.201-233, Apr. 2011.

LABAREE, D. The trouble with ed schools. New Haven, CT: Yale University Press, 2004.

MAINOTH, C. C. Os usos da literatura no ensino de história: uma perspectiva comparativa entre duas práticas pedagógicas diferenciadas. 36p. Monografia (Especialização em Residência Docente) - Departamento de História, Colégio Pedro II. Rio de Janeiro, 2013.

MARCELO, C. Empezar Con Buen Pie: Inserción a La Enseñanza para Profesores Principiantes. Revista Docencia, v. 33, p. 27-38. Santiago, 2007.

MOJE, E. B. et al. Working toward third space in content area literacy: an examination of everyday funds of knowledge and discourse. Reading Research Quarterly, Hoboken, v.39, n.1 p. 38-71, 2004.

NEUBAUER, R.; SILVEIRA, G. T.; Gestão dos sistemas escolares: quais caminhos perseguir? In: SCHWARTZMAN, S.; COX, C. (Org.). Politicas educacionais e coesão social: uma agenda latino-americana. Rio de Janeiro: Elsevier; São Paulo: IFHC, 2009.

PATTON, M. Q. Utilization-Focused Evaluation. 4. ed. SAGE Publications, 2008.

POINTER-MACE, D. Teacher practice online: sharing wisdom, opening doors. New York: Teachers College Press, 2009.

ROCHA, F. et al. É possível atingir as metas para a educação sem aumentar os gastos? Uma análise para os municípios brasileiros. Textos para Discussão, n. 15, Brasília, Tesouro Nacional. Disponível em: <http://www.tesouro.fazenda.gov.br/documents/10180/200113/TD_ Artigo_Educao.pdf >. Acesso em: 2 dez. 2015.

SHULMAN, L. S. Knowledge and teaching: foundations of the new reform. Harvard Educational Review, Cambridge, v. 57, n. 1, p. 1-27, 1987.

SILVA, M. C. M. da; O primeiro ano de docência: o choque com a realidade. In: ESTRELA, M. T. (Org.) Viver e construir a profissão docente. Porto: Porto Editora, 1997. p. 51-80. (Coleção Ciências da Educação, n. 26)

SOJA, E. W. Thirdspace: journeys to Los Angeles and other real-and-imagined places. Malden, MA: Blackw, 1996.

TARDIF, M.; RAYMOND, D.; Saberes, tempo e aprendizagem do trabalho no magistério. Educação e Sociedade, Campinas, v. 21, n. 73, p. 209-244, 2000. Disponível em: < http:/ /www. scielo.br/scielo.php?script $=$ sci_arttext\&pid $=$ S0101-73302000000400013\&lng $=$ pt\&nrm $=\mathrm{i}$ so $>$. Acesso em: 12 maio 2012.

VALENCIA, S. H. et al. Complex interactions in student teaching: lost opportunities for learning. Journal of Teacher Education, Washington, 60(3), p. 304-322, 2009. 
VEAL, W. R.; MAKINSTER, J. G. Pedagogical content knowledge taxonomies. Electronic Journal of Science Education, Georgetown, v. 3, n. 4, online, 1999. Disponível em: <http:// ejse. southwestern.edu/article/view/7615>. Acesso em: 2 dez. 2015.

VEENMAN, S. Perceived problems of beginning teachers. Review of Educational Research, Washington, v.54, n.2, p. 143-178, 1984.

VICK, M. It's a difficult matter: historical perspectives on the enduring problem of the practicum in teacher preparation. Asia-Pacific Journal of Teacher Education, Sydiney, 34, p. 181-198, 2006.

WILLIAMS, J. Teacher Educator Professional Learning in the Third Space: implications for identity and practice. Journal of Teacher Education, Washington, v. 65, n. 4, 2014.

ZABALZA, M.A. Diários de aula. Porto: Porto Editora, 1994.

ZEICHNER, K. Designing educative practicum experiences for prospective teachers. In: ZEICHNER, K.; MELNICK, S.; GOMEZ, M. L.(Ed.). Currents of reform in preservice teacher education. New York: Teachers College Press, 1996. p. 215-234.

Beyond traditional structures of student teaching. Teacher Education Quarterly, Hoboken, v. 29, p. 59-64, 2002.

University-Based Teacher Education: rethinking the connections between campus courses and field experiences in college- and university-based teacher education. Journal of Teacher Education, Washington, v. 61, p. 89-99, 2010.

\section{NOTAS}

${ }^{1}$ Estes trabalhos, assim como os demais apresentados pelos concluintes da primeira turma do PRD, estão disponíveis na Biblioteca Silvia Becher da PROPGPEC/CPII.

Recebido: $21 / 08 / 2014$

Aprovado: 23/03/2015

Contato:

Colégio Pedro II

Diretoria de Pós-Graduação

Pró-Reitora de Pós-Graduação, Pesquisa, Extensão e Cultura Campo de São Cristóvão, 177 - São Cristóvão

Rio de Janeiro |RJ|Brasil

CEP 20921-903 